\title{
Citrate as Cost-Efficient NADPH Regenerating Agent
}

\author{
Reinhard Oeggl 1,2, Timo Neumann ${ }^{1}$, Jochem Gätgens ${ }^{1}$, Diego Romano ${ }^{3}$, Stephan Noack ${ }^{1}$ \\ and Dörte Rother ${ }^{1,2 *}$
}

${ }^{1}$ Forschungszentrum Jülich GmbH, IBG-1: Biotechnology, Jülich, Germany, ${ }^{2}$ Aachen Biology and Biotechnology, RWTH Aachen University, Aachen, Germany, ${ }^{3}$ Department of Food, Environmental and Nutritional Sciences, University of Milan, Milan, Italy

\section{OPEN ACCESS}

Edited by:

Roland Wohlgemuth,

Lodz University of Technology, Poland

Reviewed by:

Rajni Hatti Kaul,

Lund University, Sweden

Luis Pina Fonseca,

Technical University of Lisbon,

Portugal

*Correspondence:

Dörte Rothe

do.rother@z-juelich.de

Specialty section:

This article was submitted to Process and Industrial Biotechnology,

a section of the journal Frontiers in Bioengineering and Biotechnology

Received: 29 March 2018 Accepted: 28 November 2018 Published: 21 December 2018

Citation:

Oeggl R, Neumann T, Gätgens J, Romano $D$, Noack $S$ and Rother $D$ (2018) Citrate as Cost-Efficient NADPH Regenerating Agent. Front. Bioeng. Biotechnol. 6:196 doi: 10.3389/fbioe.2018.00196
The economically efficient utilization of $\mathrm{NAD}(\mathrm{P}) \mathrm{H}$-dependent enzymes requires the regeneration of consumed reduction equivalents. Classically, this is done by substrate supplementation, and if necessary by addition of one or more enzymes. The simplest method thereof is whole cell NADPH regeneration. In this context we now present an easy-to-apply whole cell cofactor regeneration approach, which can especially be used in screening applications. Simply by applying citrate to a buffer or directly using citrate/-phosphate buffer NADPH can be regenerated by native enzymes of the TCA cycle, practically present in all aerobic living organisms. Apart from viable-culturable cells, this regeneration approach can also be applied with lyophilized cells and even crude cell extracts. This is exemplarily shown for the synthesis of 1-phenylethanol from acetophenone with several oxidoreductases. The mechanism of NADPH regeneration by TCA cycle enzymes was further investigated by a transient isotopic labeling experiment feeding $\left[1,5-{ }^{13} \mathrm{C}\right] c$ itrate. This revealed that the regeneration mechanism can further be optimized by genetic modification of two competing internal citrate metabolism pathways, the glyoxylate shunt, and the glutamate dehydrogenase.

Keywords: citrate oxidation, oxidoreductase screening, nicotinamide cofactor, reduction equivalent regeneration, NADPH regeneration, cofactor regeneration

\section{INTRODUCTION}

$\beta$-Nicotinamide adenine dinucleotide phosphate (NADPH) is an obligatory frequent cofactor for oxidoreductases, an important enzyme class in a manifold of academically and industrially relevant reactions (Straathof et al., 2002; Burton, 2003; Xu, 2005; Goldberg et al., 2007; Zheng et al., 2017). Unfortunately, NADPH is consumed in stoichiometric ratios during these reactions. An external NADPH addition is economically unfeasible, because it is a metastable and expensive molecule (Faber, 2011; Wu et al., 2013). Hence, several biological in vitro methods for cofactor regeneration (including also NADH) have been developed by using: (I) whole cell biocatalysis, (II) enzyme-coupled, or (III) substrate-coupled cofactor regeneration (van der Donk and Zhao, 2003; Wu et al., 2013; Marpani et al., 2017).

In the substrate coupled cofactor regeneration the backward reaction of a single $\mathrm{NAD}(\mathrm{P}) \mathrm{H}$-dependent reduction is utilized by oxidizing a second auxiliary substrate under NAD(P) consumption (Kara et al., 2014; Marpani et al., 2017). However, the utilization of the backwards reaction lowers the catalytic activity of the enzyme of interest for the target reaction. An enzyme-coupled method supplements an additional enzyme together with a suitable co-substrate to the reaction for NADPH regeneration (Liese and Villela Filho, 1999; Goldberg et al., 2007; Hall and Bommarius, 2011; Rauter et al., 2015). 
Advantageously, this method allows the enzyme of interest to operate at full catalytic activity. Yet, the supplementation of an additional enzyme also increases process costs and is less economically feasible (Tufvesson et al., 2013).

Whole cell NADPH regeneration utilizes intracellular enzymes of the host organism (Wichmann and Vasic-Racki, 2005). Thereby, whole cell regeneration intrinsically inherits the advantages of an enzyme coupled approach, which are here combined with an inexpensive enzyme production. While several NADPH regenerating reactions are available in Escherichia coli, commonly only those associated with the central carbon metabolism of $E$. coli are considered in in vitro whole cell NADPH regeneration approaches. These are in particular glucose-6-phosphate dehydrogenase, glucose dehydrogenase, and isocitrate dehydrogenase (IDH) (Wichmann and VasicRacki, 2005; Blank et al., 2010; Hummel and Gröger, 2014; Spaans et al., 2015). Though the first two enzymes are most often utilized, an IDH application would be highly interesting due to its central metabolic position and high affinity for NADPH (Schwaneberg et al., 2001).

As such IDH found already an application in in vitro screening methods of different NADPH-dependent cytochrome P450 variants (Schwaneberg et al., 2001). In short, the cultivated whole cells were placed in an in-vitro environment together with the particular substrate, isocitrate, $\mathrm{NADP}^{+}$, dimethoxysulfoxide (DMSO) and polymyxin B sulfate. Polymyxin B sulfate was added to permeabilize the cells, while DMSO is supplemented to increase substrate solubility. The intracellular isocitrate dehydrogenase (IDH) of the host E. coli was utilized to regenerate NADPH by adding the expensive specialty chemical isocitrate to the system (Schwaneberg et al., 2001). Isocitrate is converted in one physiological step to 2-oxoglutarate, reducing $\mathrm{NADP}^{+}$to NADPH. Likewise, other screening approaches have been developed, but they all suffer either from cost intensive $\mathrm{NADP}^{+}$supplementation or require further additives to avoid diffusion limitation over the cell membrane. The latter might also impair the targeted enzyme activity (Klibanov, 1997; Faber, 2011; Gerhards et al., 2012; Bornadel et al., 2016).

Building on this research, we present a whole cell NADPH regeneration in a targeted oxidoreductase reaction with the mundane bulk chemical citrate, which is converted by endogenous tricarboxylic acid (TCA) cycle enzymes. For this purpose, the specific activity of a target oxidoreductase reaction toward acetophenone was investigated in presence of citrate, when the enzyme is formulated as lyophilized whole cells (LWC) and crude cell extract (CCE) (Figure 1). Citrate is hypothesized to be isomerized by aconitase to isocitrate. Isocitrate is then decarboxylated by IDH to 2-oxoglutarate and thereby $\mathrm{NADP}^{+}$ is reduced to NADPH (Blank et al., 2010; Spaans et al., 2015). In

\footnotetext{
Abbreviations: CCE, crude cell extract; DMSO, dimethyl-sulfoxide; GDH, glutamate dehydrogenase; GR, glyoxylate reductase; LbADH, Lactobacillus brevis alcohol dehydrogenase; LWC, lyophilized whole cells; IDH, isocitrate dehydrogenase; NADH, $\beta$-1,2-nicotinamide adenine dinucleotide; NADPH, $\beta$-1,2nicotinamide adenine dinucleotide phosphate; KRED1-Pglu, Ogataea glucozyma CBS 5766 ketoreductase 1; RADH, Ralstonia species alcohol dehydrogenase; TCA, tricarboxylic acid; TIC, total ion chromatogram; XIC, extracted ion chromatogram.
}

this context it was investigated if native TCA enzyme levels are sufficient for a NADPH regeneration from citrate. Additionally, a transient isotopic labeling experiment with $\left[1,5-{ }^{13} \mathrm{C}\right]$ citrate was recorded to evaluate if citrate truly is converted along the proposed pathway and if competing side reactions occur. Citrate was also investigated as buffer substance with NADPHregenerating activity to emphasize a possible application in NADPH-dependent enzyme screenings, without the need of further additives. To verify the global transferability of this proposed system, we investigated it with three different alcohol dehydrogenases, which were all heterologously introduced into E. coli. These were ketoreductase 1 from Oogatea glycozyma (KRED1-Pglu), alcohol dehydrogenase from Ralstonia sp. (RADH), and alcohol dehydrogenase from Lactobacillus brevis (LbADH).

\section{MATERIALS AND METHODS}

\section{Materials}

All applied chemicals were purchased from Sigma Aldrich (Germany), if specified in purities $\geq 95 \%$. The cell disruption by sonification was performed on a UP 200s ultrasonic processor (Hielscher Ultrasonics GmbH, Teltow, Germany) with an S1 sonotrode (Hielscher Ultrasonics GmbH, Teltow, Germany). The reactions were incubated in an Eppendorf thermomixer comfort (Eppendorf, Hamburg, Germany) and samples were centrifuged in an Eppendorf centrifuge 5424 (Eppendorf, Hamburg, Germany). Sample analysis was performed on an Agilent technologies 1260 infinity high performance liquid chromatography system (Agilent Technologies, Santa Clara, CA, USA). Metabolic profile analysis was performed on an Agilent Technologies $6890 \mathrm{~N}$ gas chromatography system (Agilent Technologies, Santa Clara, CA, USA) coupled to a GCT Premier mass spectrometer (Waters Corporation, Milford, MA, USA). Pipetting assistance was provided by Tecan Freedom Evo 1 (Tecan, Männedorf, Swiss).

\section{Preparation of Biocatalysts}

Ogataea glucozyma CBS 5766 ketoreductase 1 (KRED1-Pglu; GenBank: AKP95857.1) on a pET-26b(+) vector, Ralstonia species alcohol dehydrogenase (RADH; PDB: 4BMS_A) on a pET-21a vector and Lactobacillus brevis alcohol dehydrogenase (LbADH; GenBank: CAD66648.1) on a pET-22b vector were heterologously expressed in E. coli BL21 (DE3) (see Supplementary S1). All were cultivated in $1 \mathrm{~L}$ auto induction medium at $37^{\circ} \mathrm{C}$ and $90 \mathrm{rpm}$ (Studier, 2005). After $4 \mathrm{~h}$ of cultivation, temperature was reduced to $20^{\circ} \mathrm{C}$. Cells were harvested after $72 \mathrm{~h}$ by centrifugation at $7,000 \mathrm{~g}$ for $45 \mathrm{~min}$ at $4{ }^{\circ} \mathrm{C}$. Harvested cells were further processed to CCE. To prepare

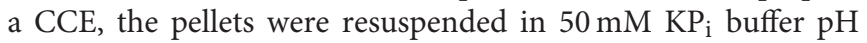
7.5 , supplied with $0.1 \mathrm{mM} \mathrm{MgCl}_{2}$. Next, the cells were disrupted by sonication at an amplitude of $40 \mu \mathrm{m}$, and a cycle time of $0.5 \mathrm{~s}$ for $40 \mathrm{~min}$ at 4 to $8{ }^{\circ} \mathrm{C}$. The solution was centrifuged at $8,000 \mathrm{~g}$ at $4^{\circ} \mathrm{C}$ for $45 \mathrm{~min}$. The supernatant was transferred into a crystallization bowl and lyophilized at $-54^{\circ} \mathrm{C}$ and $0.10 \mathrm{mbar}$. Lyophilized extract was mortared and stored at $-20^{\circ} \mathrm{C}$. The 


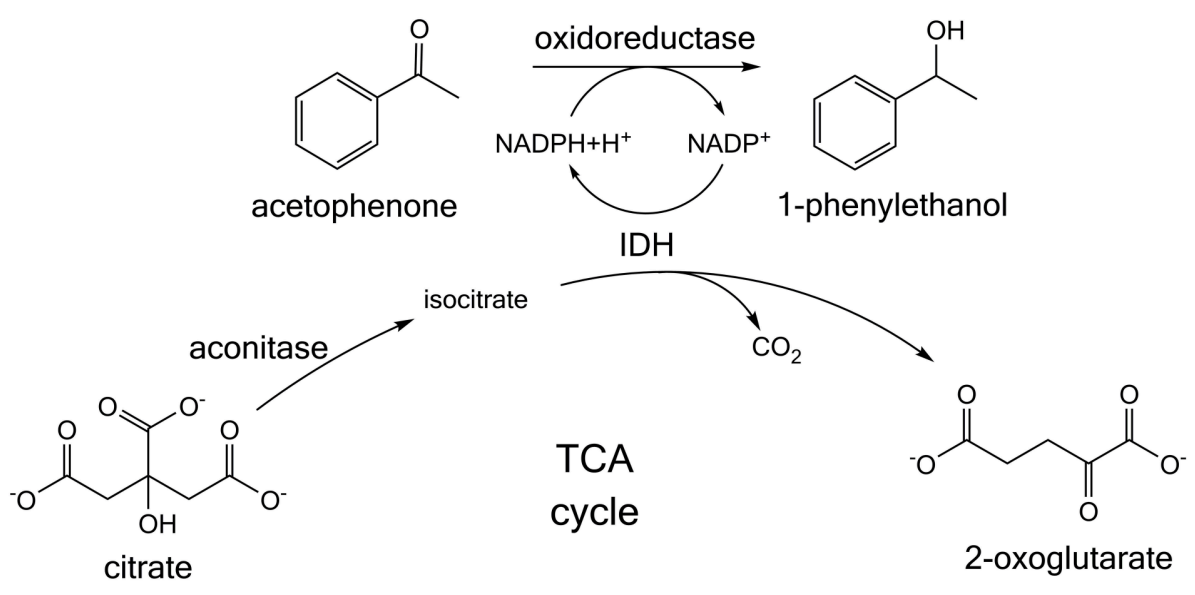

FIGURE 1 | Citrate-dependent cofactor regeneration approach for screening NADPH-dependent oxidoreductases. Acetophenone is converted to 1-phenylethanol. In the reaction NADPH is consumed, which is proposed to be regenerated by the tricarboxylic acid (TCA) cycle enzymes present in whole cells or crude cell extract. Citrate is isomerized to isocitrate and then further converted by the enzyme isocitrate dehydrogenase (IDH). In this process IDH regenerates $\mathrm{NADPH}$.

LWC catalyst was produced analogously, except cell lysis was not performed.

\section{Experimental Setup}

All experiments below were conducted in a reaction volume of $1 \mathrm{~mL}$. The activity of employed lyophilized whole cell (LWC) KRED1-Pglu was $0.1 \mathrm{U} \mathrm{mg}^{-1}$ and for the corresponding CCE $0.4 \mathrm{U} \mathrm{mg}^{1}$ in presence of $5 \mathrm{mM}$ acetophenone and $10 \mathrm{mM}$ citrate. LbADH LWC had an activity of $1.61 \mathrm{U} \mathrm{mg}^{-1}$ and as CCE $3.54 \mathrm{U}$ $\mathrm{mg}^{-1}$. In case of RADH the LWC had an activity of $0.81 \mathrm{U} \mathrm{mg}^{-1}$ and for CCE $1.78 \mathrm{U} \mathrm{mg}^{-1} .1 \mathrm{U}$ is defined $1 \mu \mathrm{mol}$ acetophenone that is converted per min by the indicated enzyme amount at defined reaction conditions of $5 \mathrm{mM}$ acetophenonen and $10 \mathrm{mM}$ citrate.

\section{Citrate Application in Whole Cell and Crude Cell Extract Setups}

KRED1-Pglu reaction solutions contained $5 \mathrm{mM}$ acetophenone, $0.1 \%(\mathrm{v} / \mathrm{v})$ DMSO and $10 \mathrm{mM}$ citrate suspended in $100 \mathrm{mM}$ $\mathrm{KP}_{\mathrm{i}}$ buffer $\mathrm{pH}$ 8. Six different conditions were tested: (I) $20 \mathrm{mg}$ $\mathrm{mL}^{-1}$ LWC, (II) $20 \mathrm{mg} \mathrm{mL}^{-1}$ CCE, (III) $20 \mathrm{mg} \mathrm{mL}^{-1} \mathrm{LWC}$ with $0.5 \mathrm{mM}$ NADPH as first positive control, (IV) $20 \mathrm{mg} \mathrm{mL}^{-1}$ CCE with $0.5 \mathrm{mM} \mathrm{NADPH}$ as second positive control, (V) $20 \mathrm{mg} \mathrm{mL}^{-1} \mathrm{LWC}$ as negative control without citrate addition, and (VI) $5 \mathrm{mg} \mathrm{mL}^{-1}$ purified enzyme. The whole setup was analogously performed with $\mathrm{RADH}$ at $\mathrm{pH} 8$ and $\mathrm{LbADH}$ at $\mathrm{pH}$ 6.5. Reactions were incubated at $30^{\circ} \mathrm{C}$ and $1,000 \mathrm{rpm}$. Samples were prepared and analyzed as described below. The activity toward acetophenone was analyzed via HPLC. Experiments were conducted in triplets.

\section{Supplementation of Isocitrate Dehydrogenase, Aconitase, and NADP ${ }^{+}$}

A basic reaction solution was prepared containing $20 \mathrm{mg} \mathrm{mL}^{-1}$ KRED1-Pglu CCE in $100 \mathrm{mM} \mathrm{KP}$ i buffer $\mathrm{pH} 8$ with $5 \mathrm{mM}$ acetophenone, $0.1 \%(\mathrm{v} / \mathrm{v}) \mathrm{DMSO}$, and $10 \mathrm{mM}$ citrate. This basic solution was tested (i) alone, (ii) with $1 \mathrm{U} \mathrm{mL}^{-1}$ isocitrate dehydrogenase (IDH), (iii) with $1 \mathrm{U} \mathrm{mL}^{-1}$ aconitase, (iv) with both enzymes supplemented to the reaction solution, and (v) with $0.5 \mathrm{mM} \mathrm{NADP}^{+}$supplemented. (vi) As negative control, the reaction solution was prepared without citrate and enzyme addition. The reaction was incubated at $30^{\circ} \mathrm{C}$ and $1,000 \mathrm{rpm}$. The screening was analogously performed for $20 \mathrm{mg} \mathrm{mL}^{-1} \mathrm{RADH}$ under the same reaction conditions and $20 \mathrm{mg} \mathrm{mL}^{-1} \mathrm{LbADH}$ with the $\mathrm{KP}_{\mathrm{i}}$ buffer set to $\mathrm{pH}$ 6.5. All experiments in this section were produced in triplicates and pipetted with the aid of a robotic station. Samples were prepared and analyzed as described below. The activity toward acetophenone was analyzed via HPLC. Experiments were carried out in triplets.

\section{$\left[1,5-{ }^{13} \mathrm{C}\right]$ Citrate Metabolic Profile Analysis}

$20 \mathrm{mg} \mathrm{mL}^{-1}$ KRED1-Pglu CCE were added to $40 \mathrm{mM}$ KPi buffer $\mathrm{pH} 8$ with $10 \mathrm{mM}$ citrate acid- $1,5-{ }^{13} \mathrm{C}, 5 \mathrm{mM}$ acetophenone, and $0.1 \%(\mathrm{v} / \mathrm{v}) \mathrm{DMSO}$. The reaction solution was incubated at $30^{\circ} \mathrm{C}$ and 1,000 rpm. Samples were taken after 0, 1, 2, 3, 4, and $5 \mathrm{~h}$. A second reaction solution was prepared with $20 \mathrm{mg} \mathrm{mL}^{-1} \mathrm{LbADH}$ CCE in $20 \mathrm{mM}$ citrate acid-1,5-13C phosphate buffer $\mathrm{pH} 6.5$ and $5 \mathrm{mM}$ acetophenone (McIlvaine, 1921). Samples were taken after $0,10,20$, and $30 \mathrm{~min}$. A negative control of the $\mathrm{LbADH}$ reaction was prepared, applying the same conditions, without citrate addition. Samples were taken after 0 and $30 \mathrm{~min}$. All samples were centrifuged at $20,000 \mathrm{~g}$ and $130 \mu \mathrm{L}$ of the supernatant were transferred into a $1.5 \mathrm{~mL}$ reaction vessel, frozen in liquid nitrogen and then stored at $-20^{\circ} \mathrm{C}$. The samples were further processed for GC-MS metabolic profile analysis as described below. Measurements were performed in singlets.

\section{Citrate-Phosphate Buffer Investigation}

Citrate phosphate buffer was prepared by combining defined amounts of $200 \mathrm{mM} \mathrm{K}_{2} \mathrm{HPO}_{4}$ with $100 \mathrm{mM}$ citrate solution. The $\mathrm{pH}$ of $\mathrm{CP}_{\mathrm{i}}$ is adjusted by the ratio of the two solutions to each other (McIlvaine, 1921). $20 \mathrm{mg} \mathrm{mL}^{-1}$ KRED1-Pglu 
CCE was added to buffered solutions that all contained $5 \mathrm{mM}$ acetophenone and $0.1 \%(\mathrm{v} / \mathrm{v})$ DMSO, but differed in source and concentration as follows: (i) $20 \mathrm{mM}$ citrate phosphate buffer $\mathrm{pH}$ 8 , (ii) $100 \mathrm{mM}$ citrate phosphate buffer $\mathrm{pH} 8$, and (iii) $100 \mathrm{mM}$ $\mathrm{KP}_{\mathrm{i}}$ buffer $\mathrm{pH} 8$ containing $10 \mathrm{mM}$ citrate. The reaction solutions were incubated at $30^{\circ} \mathrm{C}$ and $1,000 \mathrm{rpm}$. The experimental setup was repeated analogously with $\mathrm{RADH}$ at $\mathrm{pH} 8$ and $L b \mathrm{ADH}$ at $\mathrm{pH}$ 6.5. The activity toward acetophenone was analyzed via HPLC. Measurements were performed in triplets.

\section{Analytics}

Quantitative analysis was performed to determine initial activity rates in the range of maximum $10 \%$ of substrate conversion toward acetophenone on an HPLC. In case of $L b A D H$, samples were taken after $0,5,10,20,30$, and $40 \mathrm{~min}$. In case of RADH and KRED1-Pglu, samples were taken after 0, 30, 60, 120, 150, and $180 \mathrm{~min}$. Samples were diluted 1:25 in acetonitrile containing $100 \mu \mathrm{L} \mathrm{L}^{-1}$ toluene as internal standard and subsequently analyzed with a ChiralPak ID column $(5 \mu \mathrm{m}, 4.6 \times 250 \mathrm{~mm})$ at a flow of $1.0 \mathrm{~mL} \mathrm{m^{-1 }}$ under isocratic conditions of $50 \%$ acetonitrile and $50 \%$ water (purified by reverse osmosis, MilliQ) at $20^{\circ} \mathrm{C}$. Retention times: 1-phenylethanol: $3.3 \mathrm{~min}(215 \mathrm{~nm})$; acetophenone: $5.4 \mathrm{~min}(250 \mathrm{~nm})$; toluene: $6.3 \mathrm{~min}(215 \mathrm{~nm})$.

Qualitative untargeted GC-MS metabolic profile analysis was carried out under the same conditions as described by Paczia et al. (2012).

\section{RESULTS AND DISCUSSION}

\section{Citrate as Effective Agent for NADPH Regeneration in Oxidoreductase Reactions}

In aerobic organisms citrate is oxidized in the TCA cycle, while regenerating redox-equivalents. In this study, we investigated if this pathway can also be accessed in vitro in LWC to provide NADPH for a targeted oxidoreductase reaction. Since citrate uptake in $E$. coli is administered by a membrane transporter CitT, also crude cell extract (CCE) was investigated to rule out a substrate transport limitation (Pos et al., 1998). To ensure an independency of obtained results from a studied alcohol dehydrogenase, the experimental setup was investigated with KRED1-Pglu, $L b \mathrm{ADH}$, and RADH individually. As model reaction for all three oxidoreductases served the reduction of acetophenone to 1-phenylethanol under NADPH consumption (herein called target reaction; Figure 1; Leuchs and Greiner, 2011; Kulig et al., 2013; Contente et al., 2015, 2016). If citrate is converted by endogenous TCA cycle enzymes NADPH would be generated and thus a 1-phenylethanol formation would be observable. The possibility of endogenous NADPH levels to suffice for catalytic activity or other endogenous sources to regenerate $\mathrm{NADPH}$ was investigated by a LWC setup with acetophenone, but without citrate addition. The possibility that citrate could also be converted by the applied alcohol dehydrogenases was ruled out by performing the model reaction with purified KRED1-Pglu, LbADH, and RADH individually. Also NADPH was supplemented instead of citrate to rule out a limitation of available NADPH.

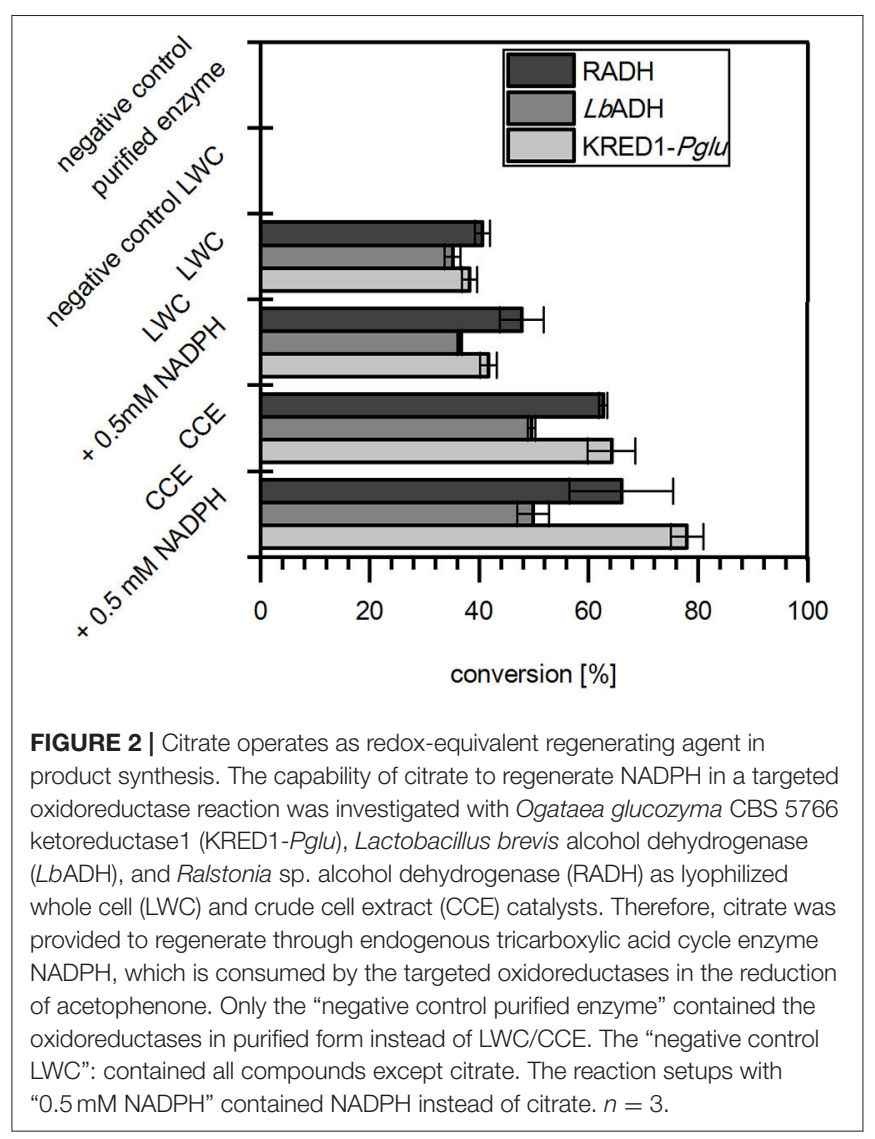

In the results all three targeted oxidoreductases were active in LWC and CCE formulation when citrate was present and reduced acetophenone (Figure 2). In absence of citrate LWCs did not convert any acetophenone, which proves that citrate is neither substrate of the selected oxidoreductases nor does citrate directly reduce $\mathrm{NADP}^{+}$. Moreover, the reaction with purified enzyme also did not display any activity, which demonstrates that citrate is not converted by the target oxidoreductase to gain NADPH. Together this indicates strongly, that citrate is converted by endogenous TCA cycle enzymes of both the CCE and LWC. More importantly, it verifies that citrate is applicable in vitro as inexpensive cosubstrate to achieve good product conversion by whole cell NADPH regeneration.

A more detailed look at relative initial activities under the investigated conditions demonstrates CCEs to be more active than LWCs (Figure 3). This indicates indeed mass transport of citrate as limiting to some extent. A prior cell lysis to synthesis application may thus circumvent such a limitation and make an application of CCE recommendable.

An additional observation shows higher initial activities by direct NADPH supplementation than with CCE (Figure 3). This indicates that under citrate addition the reaction is limited in $\mathrm{K}_{\mathrm{M}}$ for NADPH. For this matter three factors are conceivable: (i) endogenous $\mathrm{NADP}^{+}$amounts are too low, (ii) the present TCA cycle enzymes do not suffice to regenerate NADPH fast enough, and (iii) untargeted side-reactions in the CCE and LWC setup may compete with the targeted oxidoreductase reaction 


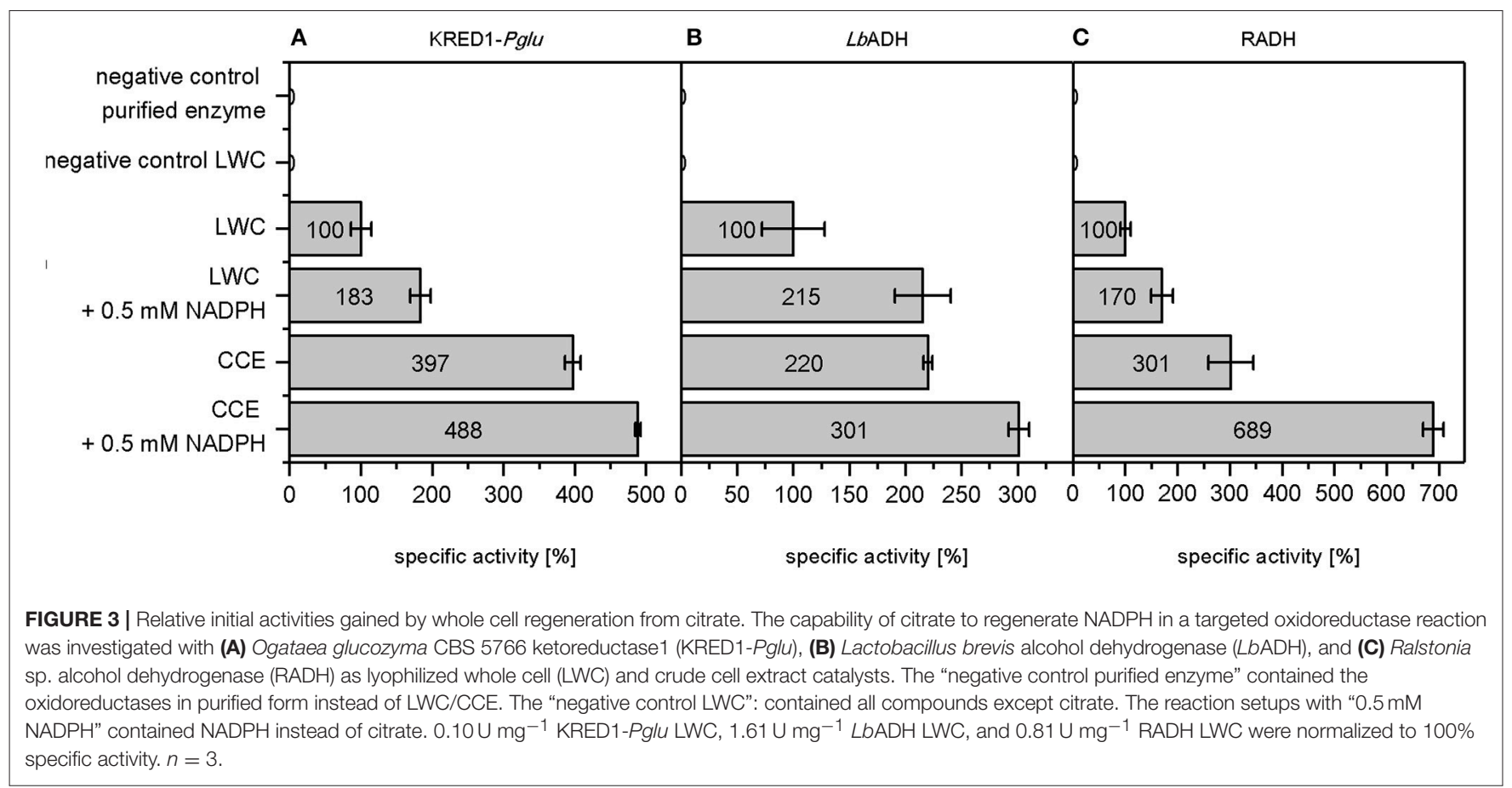

for NADPH. In all three cases an excess of NADPH saturates the demand of all NADPH-dependent enzymes in the reaction, allowing the targeted oxidoreductases to operate at $\mathrm{V}_{\max }$.

In conclusion these first findings demonstrate citrate as a well applicable, inexpensive cosubstrate for NADPH regeneration during product synthesis. A detailed analysis of initial activities shows that a mass transport limitation for citrate reduces activities in LWCs. Hence, an application of this NADPH regeneration method would be preferred in CCE. During initial activity analysis it was also observed that all investigated enzymes do not operate at $V_{\max }$, which was revealed by the addition of $0.5 \mathrm{mM}$ NADPH. Subsequently, the reason for this limitation is investigated on a cellular basis. Here, three different circumstances were proposed as limiting an operation at $\mathrm{V}_{\max }$ : (i) too low endogenous $\mathrm{NADP}^{+}$levels, (ii) too low TCA cycle enzyme expression, or (iii) untargeted side-reactions that deplete $\mathrm{NADPH}$.

\section{TCA Cycle Enzymes and Endogenous NADP $^{+}$Levels Are Sufficient for NADPH Regeneration}

First the potential of an inherent limitation caused by either low basal levels of the involved TCA cycle enzymes aconitase and IDH (Figure 1) or insufficient endogenous $\mathrm{NADP}^{+}$levels was investigated. To investigate the first case, both enzymes were supplemented in CCE experiments individually as well as in combination (Figure 4). For the second case $0.5 \mathrm{mM} \mathrm{NADP}^{+}$ were supplemented to a CCE setup. The negative control neither contained citrate nor any supplemented aconitase, IDH, or $\mathrm{NADP}^{+}$. As positive control the CCE of each of the three oxidoreductases KRED1-Pglu, LbADH, and RADH, was added to a buffered reaction solution which contained acetophenone and citrate, but no additional enzymes.

The recorded initial activities of the positive control and supplemented aconitase and IDH both individually and combined were approximately equally fast (Figure 4). This indicates endogenous enzyme levels as indeed sufficient for citrate metabolism. Literature supports this claim as IDH is naturally well overexpressed in E. coli (Vasquez and Reeves, 1979; Schwaneberg et al., 2001).

The supplementation of $\mathrm{NADP}^{+}$also did not affect any activity increase (Figure 4). This indicates $\mathrm{NADP}^{+}$also as not limiting in the setup. The finding is reinforced by an estimation of endogenous $\mathrm{NADP}^{+}$amounts based on literature values published by Bennett et al. (2009) and Chemler et al. (2010). Based on their values $\mathrm{NADP}^{+} / \mathrm{NADPH}$ molecules were estimated to be in excess by a magnitude of $10^{7}$ to the targeted oxidoreduteases (estimation see Supplementary S3.1).

Together these findings rule out a possibility of a limitation caused by insufficient TCA enzymes to regenerate NADPH. Further, intrinsically provided $\mathrm{NADP}^{+}$levels are abundant enough as to not limit catalytic rates of the targeted oxidoreductase reactions. Thus, the potential of undesired side reaction as cause for the observed limitation has to be investigated.

\section{$\left[1,5-{ }^{13} \mathrm{C}\right]$ Citrate Metabolic Profile Analysis Identifies Limiting Side Reactions}

To identify if citrate is funneled into side reactions a transient isotopic labeling experiment with ${ }^{13} \mathrm{C}$-labeled citrate was performed. Acetophenone and $\left[1,5-{ }^{13} \mathrm{C}\right] \mathrm{citrate}$ were added to a buffered reaction mixture with $\mathrm{LbADH} \mathrm{CCE}$ catalyst 


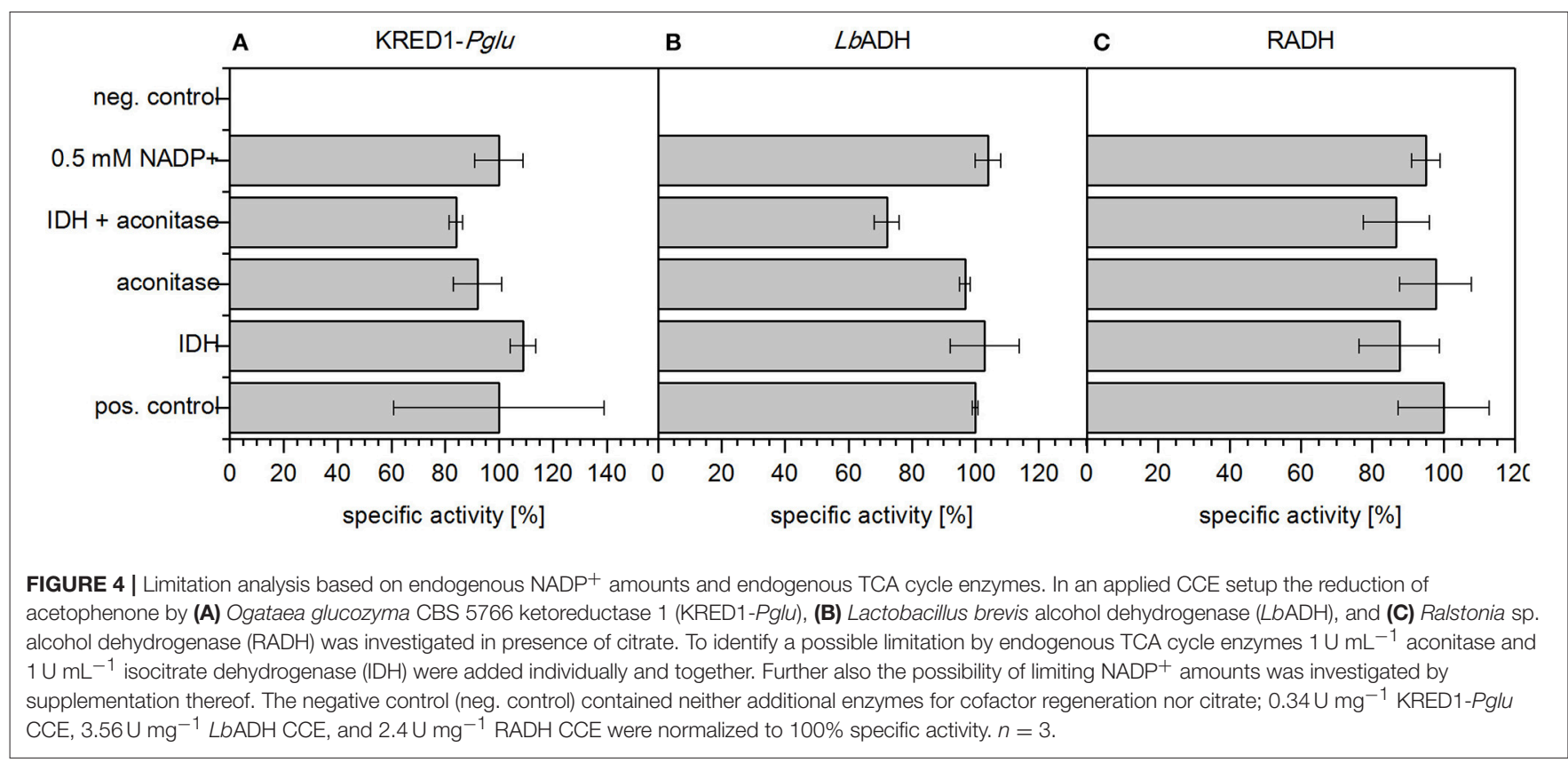

(for the same experiment performed with KRED1-Pglu see Supplementary S2.3). A GC-ToF-MS analysis recorded the consumption of citrate, the formation of 1-phenylethanol and, most importantly, for the specific labeling enrichment in several TCA cycle intermediates downstream of citrate. Any further implications from citrate conversion, which did not directly affect NADPH regeneration, are beyond the scope of this study and were thus not considered.

In principle, three proximate competing routes to the conversion of citrate along the TCA cycle are conceivable (Figure 5): (i) 2-oxoglutarate is partly reduced to glutamate by glutamate dehydrogenase (GDH); (ii) isocitrate is partly split into succinate and glyoxylate, which both are further converted to malate and (iii) glyoxylate is partly reduced to glycolate by glyoxylate reductase (GR; Ornston and Ornston, 1969; Csonka and Fraenkel, 1976; Spaans et al., 2015).

Ideally, only the TCA cycle is involved in citrate metabolization, because only by this mode NADPH is regenerated in the targeted manner by IDH. Accordingly, ${ }^{13} \mathrm{C}$ labeling would be introduced into the TCA cycle intermediates and malate would accumulate. In the first competing case, the GDH reaction would partly consume the NADPH formed by $\mathrm{IDH}$, resulting in an overall lowered NADPH regeneration capacity and an accumulation of glutamate. In the second case, NADPH regeneration by IDH would be partly skipped and, again, accumulation of malate is expected. Finally, the third case would be the worst one, since the GR reaction would directly compete for the available NADPH pool without adding any reduction equivalents to it (Figure 5).

From the total ion chromatograms (TIC) it can be seen that citrate is completely converted within the first $20 \mathrm{~min}$ of the reaction (Figure 6). In the same pattern the product concentration of the target reaction, 1-phenylethanol, increases.
The TCA cycle intermediate succinate was already present at the start of the reaction and no significant change was observed. By contrast, malate and glutamate strongly accumulated along the CCE experiment. For glycolate, only a minor elevation was recorded over time (Figure 6). The corresponding negative control, which contained all reactants like the reaction solution except for citrate, did not exhibit any product formation and no significant elevation of TCA cycle intermediates (Supplementary S2.2).

The obtained TIC findings suggest all presented pathways for citrate metabolism (Figure 5) to be indeed active under CCE conditions. Foremost, the observation of 1-phenylethanol in the reaction solution (Figure 6) and its absence in the negative control (Supplementary S2.2) substantiates the theory of an active TCA cycle, because required NADPH can only be gained by a conversion through IDH. The accumulation of glutamate and glycolate also indicates a presence of side-reactions caused by GR and GDH, which lower NADPH amounts for the target oxidoreductase reaction. To validate an occurrence of these side reactions the transition of the ${ }^{13} \mathrm{C}$ labeled carbon atom in the metabolite profile was investigated.

In extracted ion chromatograms (XIC) the distinct mass fragments for the unlabeled and ${ }^{13} \mathrm{C}$ labeled metabolites were tracked. Firstly, unlabeled succinate dissipates over the reaction time, while ${ }^{13} \mathrm{C}$-labeling from citrate is introduced via the TCA cycle and glyoxylate shunt (Figure 7). This indicates a continuous turnover of the succinate pool, leading to a stable metabolite level during the CCE experiment (Figure 5). For malate and glutamate, the fractions of ${ }^{13} \mathrm{C}$-labeled and unlabeled species elevated to an equal extent, indicating that both metabolites represent dead-end pools for (i) citrate metabolism along the TCA cycle, (ii) the GDH by-pass, and (iii) the glyoxylate shunt. Thus, the selected XIC verifies all three citrate pathway 


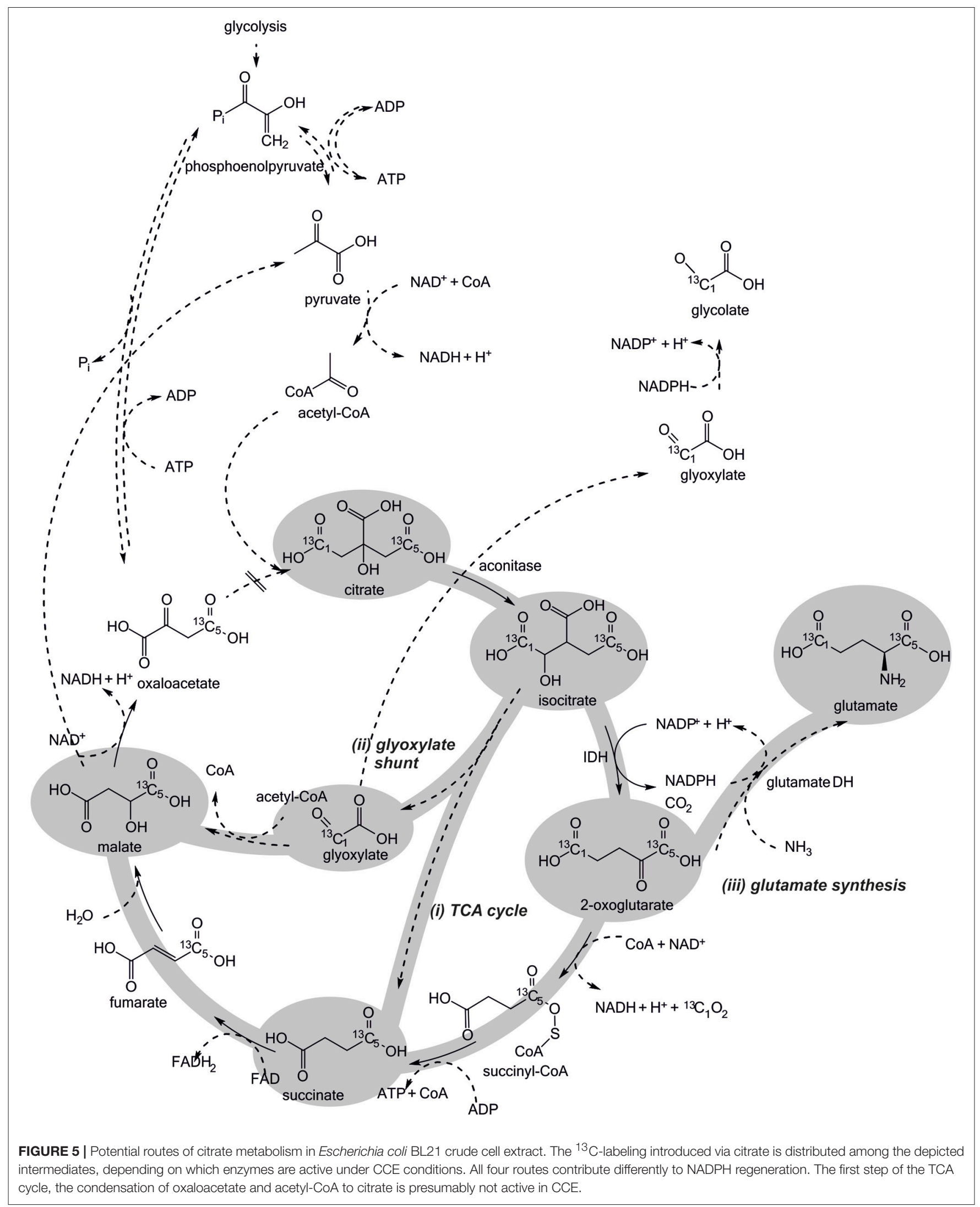




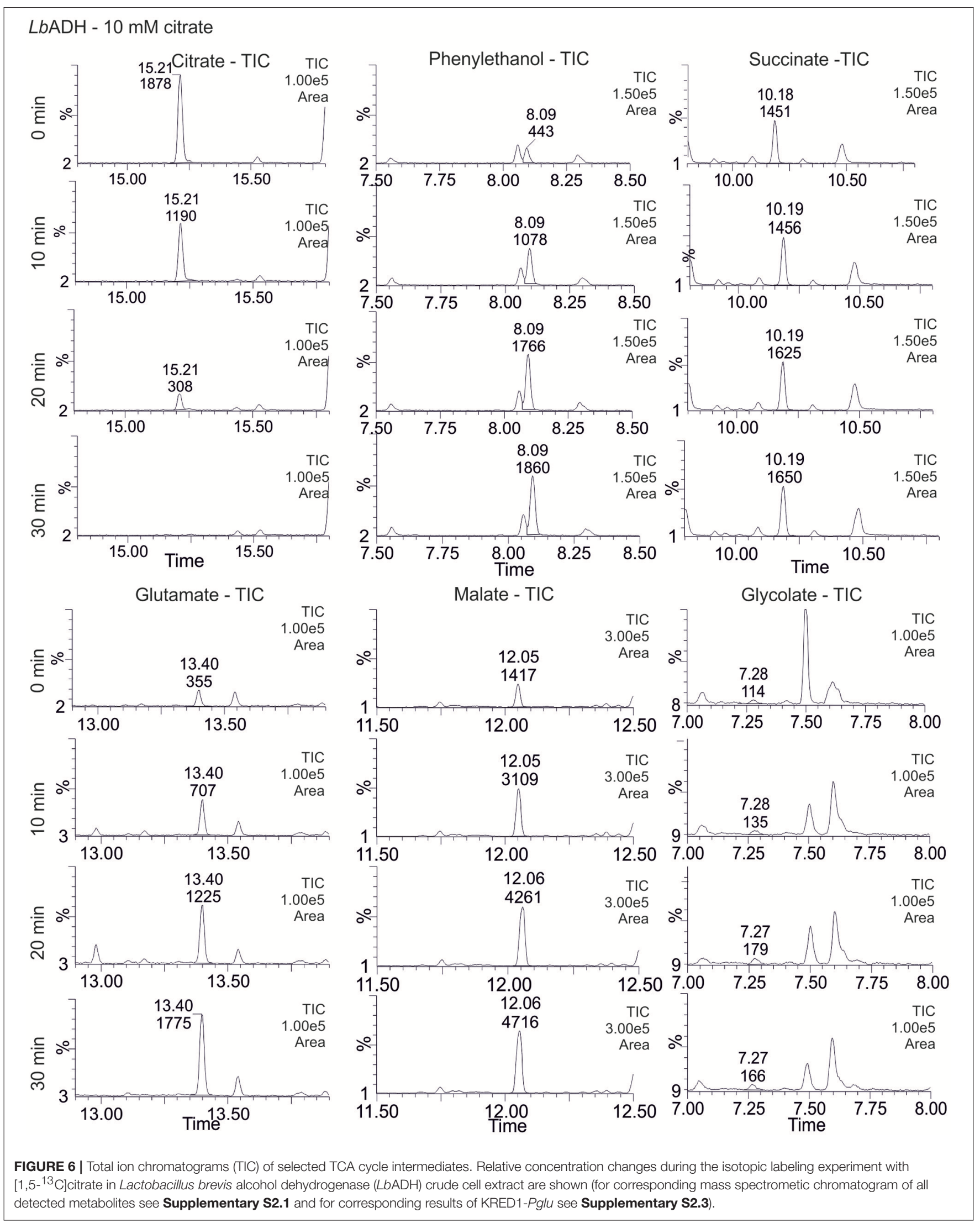



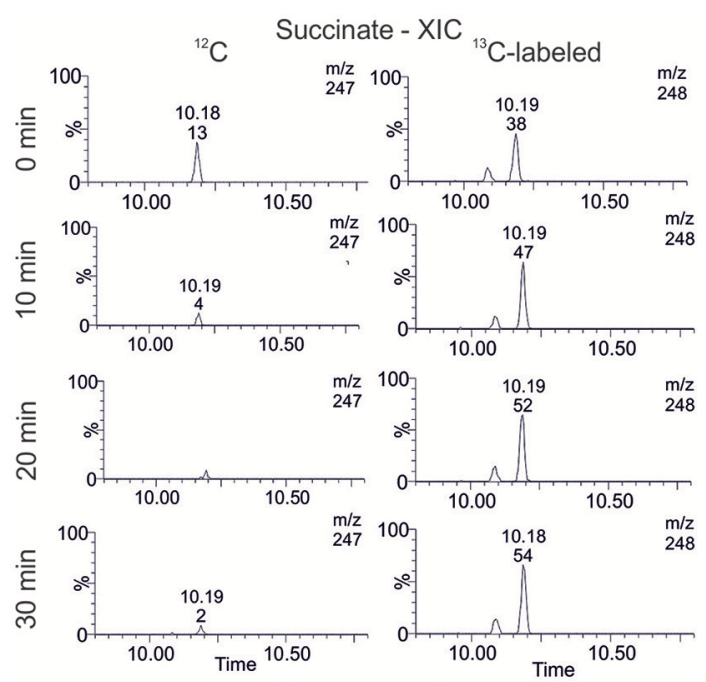

$m / z$
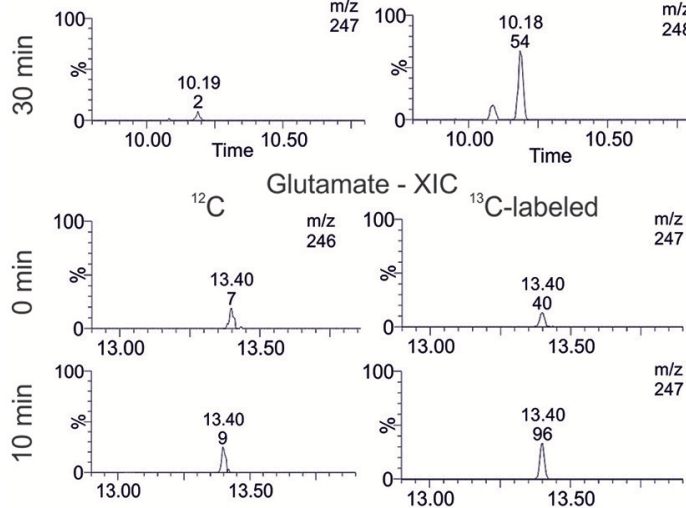

248
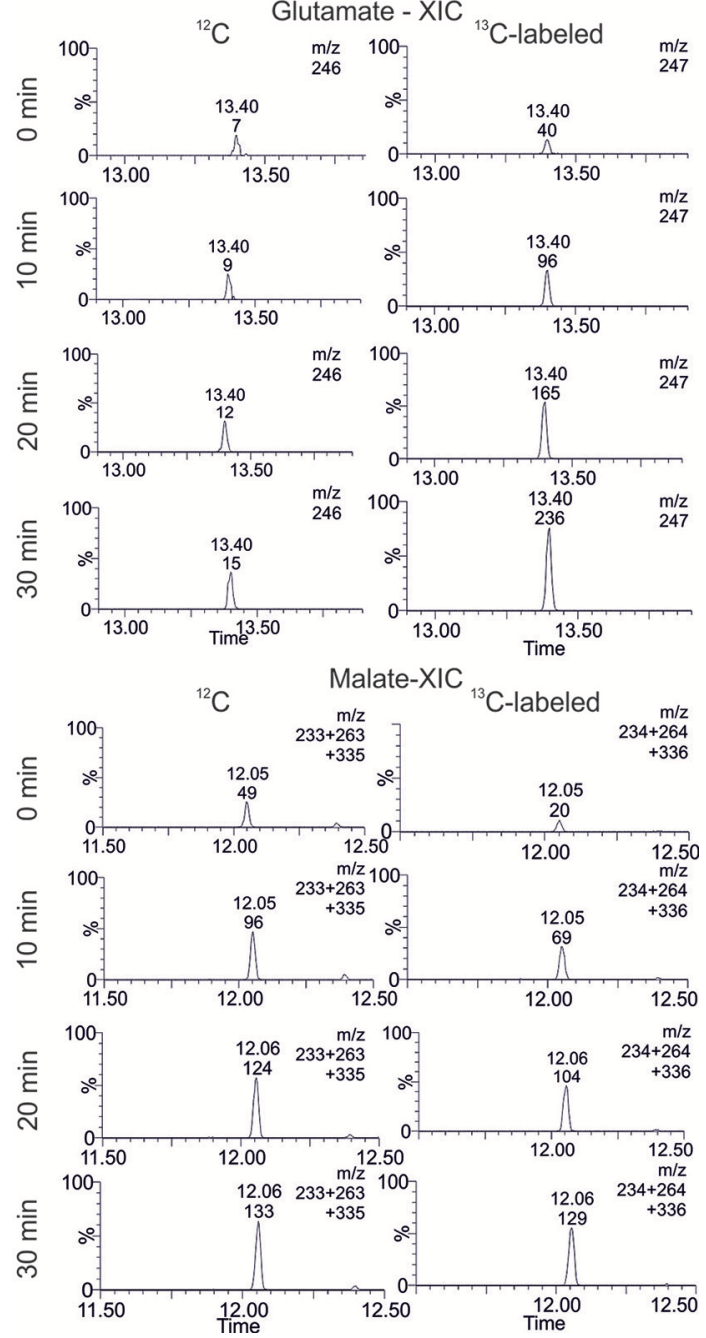

FIGURE 7 | Extracted ion chromatogram (XIC) of selected TCA cycle intermediates. The accumulation and dissipation of ${ }^{12} \mathrm{C}$ and ${ }^{13} \mathrm{C}$ labeled species during the isotopic labeling experiment with $\left[1,5-{ }^{13} \mathrm{C}\right]$ citrate in Lactobacillus brevis alcohol dehydrogenase $(\mathrm{LbADH})$ crude cell extract are displayed (corresponding results of KRED1-Pglu see Supplementary S2.4). as active. Yet, it did not grant quantitative information on the distribution ratio of citrate metabolism between the three pathways. An estimation of the extent of the GDH by-pass and the glyoxylate shunt is nonetheless possible with literature values. In the gloxylate shunt acetyl-CoA is required to obtain malate (Figure 5). Based on literature values the acetyl-CoA concentration in the setup can be estimated to range of 0.04 to 0.03 mM (estimation Supplementary S3.2; Bennett et al., 2009). Accordingly, only $0.4 \%$ of citrate would dissipate in this pathway. This estimation adjoined with the insignificant findings of GDH product in the TIC chromatogram indicates the glyoxylate shunt as dissipation source for citrate as negligible. In case of glutamate such an estimation is not possible and any ratio on the loss would be speculative. Yet, E. coli is a strong glutamate producer, which is indicated by the fact that the most abundant intracellular E. coli metabolite is glutamate (Bennett et al., 2009). A loss in this side reaction could be substantial in dependence of available $\mathrm{NH}_{3}$, which is unfortunately unknown. The ratio of this side reactions could be clarified in the future with a $\left[2,4-{ }^{13} \mathrm{C}\right]$ citrate tracer, which gives a distinct ${ }^{13} \mathrm{C}$-labeling pattern for the origin of each metabolite (see Supplementary S4).

In summary, the transient ${ }^{13} \mathrm{C}$ isotope labeling verified the theory of NADPH regeneration through TCA cycle enzymes. However, the citrate metabolism into the glyoxylate shunt, glycolate synthesis, and glutamate synthesis were identified as competing side reactions (Figure 5). The glyoxylate shunt and glycolate synthesis was determined of minor to insignificant importance in the citrate depletion, because required intracellular acetyl-CoA levels are estimated to be too low to substantially promote a conversion of citrate through this pathway. The extent of NADPH loss by glutamate could unfortunately not be quantified, as the concentration of ammonia in the setup was unknown. Yet, all herein obtained findings indicate glutamate synthesis as limitation cause for NADPH regeneration efficiency. Interestingly, by the sheer quantity of present targeted oxidoreductase to all other host enzymes it could be assume to be more likely that the majority of NADPH is consumed by the target oxidoreductase. Acetophenone, however, is an artificial substrate for the targeted oxidoreductases (KRED1Pglu, LbADH, RADH), while citrate and the metabolites of the TCA cycle are natural substrates of the primary metabolism. Thus, it can be speculated that the host enzymes and in this particular case the GDH exhibit a higher NADPH turnover rate than the targeted oxidoreductase. In future applications this issue could be solved by genetically engineering the efficiency of the glutamate synthesis or introducing an ammonium limitation that would slow GDH synthesis and thereby the depletion of NADPH. Also the inactivation of the glyoxylate shunt in E. coli by cultivating it on glucose as sole carbon and energy source could enhance the NADPH regeneration efficiency from citrate (Noronha et al., 2000; Phue and Shiloach, 2004; Phue et al., 2005).

In summary these gained findings illustrate very well that citrate is capable to provide NADPH to target product conversions. An application in investigation of initial activity rates is presently limited by the reported side reactions. However, a relative initial activity comparison may already be applicable, 


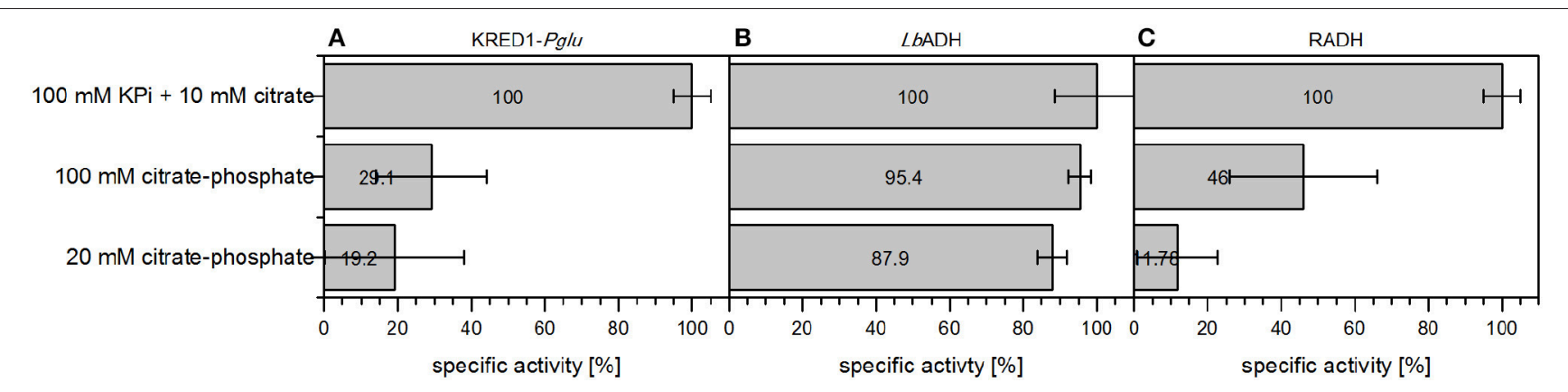

FIGURE 8 | Comparison of citrate-phosphate buffer against citrate addition in terms of specific initial activities of different oxidoreductases. The required cofactor for the NADPH-dependent oxidoreductases is regenerated by either $10 \mathrm{mM}$ citrate supplementation in an environment using $100 \mathrm{mM}$ KP $\mathrm{j}$ buffer or directly applying citrate as 20 or $100 \mathrm{mM}$ citrate-phosphate buffer. (A) was performed with KRED1-Pglu at pH 8, (B) was performed with $\angle b A D H$ at pH 6.5, and (C) was performed with RADH at pH 8. $0.34 \mathrm{U} \mathrm{mg}^{-1} \mathrm{KRED} 1-P g l u$ CCE, $3.56 \mathrm{U} \mathrm{mg}^{-1} \mathrm{LbADH}$ CCE, and $2.4 \mathrm{U} \mathrm{mg}^{-1}$ RADH CCE were normalized to $100 \%$ specific activity. $n=3$.

and implementation of necessary genetic alterations could unfold the full potential of this method.

\section{NADPH Regenerating Buffer for Initial Activity Measurements of Oxidoreductases}

The potential for initial activity comparison by this method could be increased by applying citrate as in vitro reaction environment in form of citrate-phosphate $\left(\mathrm{CP}_{\mathrm{i}}\right)$ buffer. This buffer is a universal buffer, which covers a $\mathrm{pH}$ range from 2 to 8 . Interestingly, this it would allow a relative activity comparison of oxidoreductases in screenings without the need to switch buffer types. Especially, because buffer types are reported to also affect oxidoreductase activity (Zhao, 2005; Kulig et al., 2013). All three targeted oxidoreductases were applied as CCE in $100 \mathrm{mM} \mathrm{CP_{i }}$ buffer and $20 \mathrm{mM} \mathrm{CP}_{\mathrm{i}}$ buffer and compared against $100 \mathrm{mM} \mathrm{KP_{i }}$ buffer with $10 \mathrm{mM}$ citrate supplementation.

KRED1-Pglu and RADH CCE exhibited only reduced specific activity in $100 \mathrm{mM} \mathrm{CP}$ and accordingly with $20 \mathrm{mM} \mathrm{CP}_{\mathrm{i}}$, when compared to the standard reaction conditions (Figures 8A,C). For $L b \mathrm{ADH}$ almost no activity loss was observed, when $100 \mathrm{mM}$ $\mathrm{CP}_{\mathrm{i}}$ was compared against the standard conditions (Figure 8B). Even at $20 \mathrm{mM} \mathrm{CP}$ only a minor decline in activity was determined.

This observation could be caused by the $\mathrm{pH}$-dependent buffer composition of the reactions. Both KRED1-Pglu and RADH have their $\mathrm{pH}$ optimum for reduction at 8 , while $\mathrm{LbADH}$ performs best at pH 6.5 (Leuchs and Greiner, 2011; Kulig et al., 2013; Contente et al., 2015). $\mathrm{CP}_{\mathrm{i}}$ buffer consists of a distinct mixture of a $\mathrm{K}_{2} \mathrm{HPO}_{4}$ and a citrate stock solution. The acidic citrate part represent only a minor fraction at a higher $\mathrm{pH}$ (McIlvaine, 1921). Hence, $100 \mathrm{mM} \mathrm{CP}$ pH 8 contains $1.2 \mathrm{mM}$ citrate and $20 \mathrm{mM} \mathrm{CP}$ only $0.24 \mathrm{mM}$. At pH 6 citrate is present in $13 \mathrm{mM}$ concentrations in $100 \mathrm{mM} \mathrm{CP}$ buffer and in the $20 \mathrm{mM}$ setup $2.6 \mathrm{mM}$ concentrations. The results for $\mathrm{LbADH}$ indicate this concentration of $2.6 \mathrm{mM}$ in the $20 \mathrm{mM} \mathrm{CP}$ setup as sufficient for a catalytic comparison. This concentration is calculated to also be present in $100 \mathrm{mM} \mathrm{CP}_{\mathrm{i}}$ buffer $\mathrm{pH} 7.7$ (McIlvaine, 1921). Hence, $100 \mathrm{mM} \mathrm{CP}$ buffer would allow a $\mathrm{pH}$ screening under consistent buffer components in a range of $\mathrm{pH} 2$ to 7.7. The clear advantage for screenings is, that effects of changing buffer salts can be neglected (Zhao, 2005; Kulig et al., 2013).

Conclusively, $\mathrm{CP}_{\mathrm{i}}$ offers the possibility of a universal buffer environment for oxidoredcutase applications in a buffer range of $\mathrm{pH} 2$ to 7.7. This could for instance presently be employed for relative activity comparisons. However, it should be treated cautiously as the applied enzymes in this study exhibit different activities toward the used artificial substrate acetophenone. Thus, the regeneration capacity for NADPH in the present stage may be insufficient for reactions with high $\mathrm{V}_{\max }$.

\section{CONCLUSION}

In summary, the cheap bulk chemical citrate was proven to regenerate NADPH by conversion through the endogenous TCA cycle in a CCE and LWC setup. CCE setups yielded higher specific activities than LWCs, most likely due to the absence of a diffusion barrier. An analysis of initial activities revealed a limitation of the recombinant oxidoreductases, which was thought to be due to too low NADPH levels to achieve $\mathrm{V}_{\max }$. Here, endogenous TCA enzyme levels and $\mathrm{NADP}^{+}$amounts could be excluded as limitation origin as experiments found them to be present in abundance. A transient isotopic labeling experiment feeding $\left[1,5-{ }^{13} \mathrm{C}\right]$ citrate verified citrate dissipation in the glyoxylate shunt to a minor extent and a supposedly significant loss of NADPH in glutamate synthesis. In the future, the glyoxylate shunt could be inactivated through cultivation of $E$. coli on glucose as sole carbon source. Glutamate synthesis could be lowered by feeding only defined amounts of ammonia. Apart from the characterization of the citrate regeneration, citrate was also successfully applied as $\mathrm{CP}_{\mathrm{i}}$ reaction buffer for targeted oxidoreductase reactions. Hence, citrate is proposed as applicable in comparative activity screenings of oxidoreductases in a range of $\mathrm{pH} 6.5$ to 7.7. Advantageously, this allows an inexpensive $\mathrm{NADPH}$ regeneration in a simple reaction setup, without the need of extensive additives. This may become even more appealing once necessary genetic optimizations in E. coli have been made. Nonetheless, the described method is already in the present form well applicable to produce satisfying conversions 
in product synthesis. Notably, this study also uncovered that further steps of the TCA cycle are active, in which also NADH is regenerated. Though this was not further investigated in this study, the application of citrate may even be broadened to $\mathrm{NADH}$-dependent enzymes.

\section{AUTHOR CONTRIBUTIONS}

RO and DöR designed the study and prepared the manuscript. The enzyme KRED1-Pglu from Ogataea glucozyma CBD 5766 was contributed by DiR. TN carried out the experimental setup and procedure. RO, TN, and JG carried out the analytics and evaluation of results. RO and DöR supervised the experimental work. RO, JG, DiR, SN, and DöR helped to finalize the manuscript. All authors approved the final manuscript.

\section{REFERENCES}

Bennett, B. D., Kimball, E. H., Gao, M., Osterhout, R., Van Dien, S. J., and Rabinowitz, J. D. (2009). Absolute metabolite concentrations and implied enzyme active site occupancy in Escherichia coli. Nat. Chem. Biol. 5, 593-599. doi: $10.1038 /$ nchembio. 186

Blank, L. M., Ebert, B. E., Buehler, K., and Bühler, B. (2010). Redox biocatalysis and metabolism: molecular mechanisms and metabolic network analysis. Antioxid. Redox Signal. 13, 349-394. doi: 10.1089/ars.2009.2931

Bornadel, A., Hatti-Kaul, R., Hollmann, F., and Kara, S. (2016). Enhancing the productivity of the bi-enzymatic convergent cascade for $\varepsilon$-caprolactone synthesis through design of experiments and a biphasic system. Tetrahedron 72, 7222-7228. doi: 10.1016/j.tet.2015.11.054

Burton, S. G. (2003). Oxidizing enzymes as biocatalysts. Trends Biotechnol. 21, 543-549. doi: 10.1016/j.tibtech.2003.10.006

Chemler, J. A., Fowler, Z. L., McHugh, K. P., and Koffas, M. A. G. (2010). Improving NADPH availability for natural product biosynthesis in Escherichia coli by metabolic engineering. Metab. Eng. 12, 96-104. doi: 10.1016/j.ymben.2009.07.003

Contente, M. L., Serra, I., Brambilla, M., Eberini, I., Gianazza, E., De Vitis, V., et al. (2015). Stereoselective reduction of aromatic ketones by a new ketoreductase from Pichia glucozyma. Appl. Microbiol. Biotechnol. 100, 193-201. doi: 10.1007/s00253-015-6961-y

Contente, M. L., Serra, I., Palazzolo, L., Parravicini, C., Gianazza, E., Eberini, I., et al. (2016). Enzymatic reduction of acetophenone derivatives with a benzil reductase from Pichia glucozyma (KRED1-Pglu): electronic and steric effects on activity and enantioselectivity. Org. Biomol. Chem. 14, 3404-3408. doi: 10.1039/C6OB00047A

Csonka, L. N., and Fraenkel, D. G. (1976). Pathways of NADPH formation in Escherichia coli. J. Biol. Chem. 252, 3382-3391.

Faber, K. (ed.). (2011). "Introduction and Background Information," in Biotransformations in Organic Chemistry (Berlin, Heidelberg: Springer), 1-30.

Gerhards, T., Mackfeld, U., Bocola, M., von Lieres, E., Wiechert, W., Pohl, M., et al. (2012). Influence of organic solvents on enzymatic asymmetric carboligations. Adv. Synth. Catal. 354, 2805-2820. doi: 10.1002/adsc.201200284

Goldberg, K., Schroer, K., Lütz, S., and Liese, A. (2007). Biocatalytic ketone reduction-a powerful tool for the production of chiral alcoholspart II: whole-cell reductions. Appl. Microbiol. Biotechnol. 76, 249-255. doi: 10.1007/s00253-007-1005-x

Hall, M., and Bommarius, A. S. (2011). Enantioenriched compounds via enzymecatalyzed redox reactions. Chem. Rev. 111, 4088-4110. doi: 10.1021/cr200013n

Hummel, W., and Gröger, H. (2014). Strategies for regeneration of nicotinamide coenzymes emphasizing self-sufficient closed-loop recycling systems. J. Biotechnol. 191, 22-31. doi: 10.1016/j.jbiotec.2014.07.449

\section{FUNDING}

This project was funded by the Helmholtz-Association in frame of the young investigators group synthetic enzyme cascades.

\section{ACKNOWLEDGMENTS}

Many thanks go to Jannick Kappelmann providing us with the isocitrate dehydrogenase form Bacillus subtilis. Further we thank Jennifer Goldmanns for her experimental work on the subject.

\section{SUPPLEMENTARY MATERIAL}

The Supplementary Material for this article can be found online at: https://www.frontiersin.org/articles/10.3389/fbioe. 2018.00196/full\#supplementary-material

Kara, S., Schrittwieser, J. H., Hollmann, F., and Ansorge-Schumacher, M. B. (2014). Recent trends and novel concepts in cofactor-dependent biotransformations. Appl. Microbiol. Biotechnol. 98, 1517-1529. doi: 10.1007/s00253-013-5441-5

Klibanov, A. (1997). Why are enzymes less active in organic solvents than in water? Trends Biotechnol. 15, 97-101. doi: 10.1016/S0167-7799(97)01013-5

Kulig, J., Frese, A., Kroutil, W., Pohl, M., and Rother, D. (2013). Biochemical characterization of an alcohol dehydrogenase from Ralstonia sp. Biotechnol. Bioeng. 110, 1838-1848. doi: 10.1002/bit.24857

Leuchs, S., and Greiner, L. (2011). Alcohol dehydrogenase from Lactobacillus brevis: a versatile robust catalyst for enantioselective transformations. Chem. Biochem. Eng. Q. 25, 267-281. Available online at: https://hrcak.srce.hr/69863

Liese, A., and Villela Filho, M. (1999). Production of fine chemicals using biocatalysis. Curr. Opin. Biotechnol. 10, 595-603. doi: 10.1016/S0958-1669(99)00040-3

Marpani, F., Pinelo, M., and Meyer, A. S. (2017). Enzymatic conversion of $\mathrm{CO}_{2}$ to $\mathrm{CH}_{3} \mathrm{OH}$ via reverse dehydrogenase cascade biocatalysis: quantitative comparison of efficiencies of immobilized enzyme systems. Biochem. Eng. J. 127, 217-228. doi: 10.1016/j.bej.2017.08.011

McIlvaine, T. C. (1921). A buffer solution for colorimetric comparison. J. Biol. Chem. 49, 183-186.

Noronha, S. B., Yeh, H. J. C., Spande, T. F., and Shiloach, J. (2000). Investigation of the TCA cycle and the glyoxylate shunt in Escherichia coli BL21 and JM109 using ${ }^{13} \mathrm{C}-\mathrm{NMR} / \mathrm{MS}$. Biotechnol. Bioeng. 68, 316-327. doi: 10.1002/(SICI)1097-0290(20000505)68:3<316::AID-BIT10>3.0.CO;2-2

Ornston, L. N., and Ornston, M. K. (1969). Regulation of glyoxylate metabolism in Escherichia coli K-12. J. Bacteriol. 98, 1098-1108.

Paczia, N., Nilgen, A., Lehmann, T., Gätgens, J., Wiechert, W., and Noack, S. (2012). Extensive exometabolome analysis reveals extended overflow metabolism in various microorganisms. Microb. Cell Fact. 11:122. doi: 10.1186/1475-2859-11-122

Phue, J.-N., Noronha, S. B., Hattacharyya, R., Wolfe, A. J., and Shiloach, J. (2005). Glucose metabolism at high density growth of E. coli $B$ and E. coli $K$ : differences in metabolic pathways are responsible for efficient glucose utilization in E. coli $B$ as determined by microarrays and Northern blot analyses. Biotechnol. Bioeng. 90, 805-820. doi: 10.1002/bit.20478

Phue, J. N., and Shiloach, J. (2004). Transcription levels of key metabolic genes are the cause for different glucose utilization pathways in E. coli B (BL21) and E. coli K (JM109). J. Biotechnol. 109, 21-30. doi: 10.1016/j.jbiotec.2003.10.038

Pos, K. M., Dimroth, P., and Bott, M. (1998). The Escherichia coli citrate carrier CitT: a member of a novel eubacterial transporter family related to the 2oxoglutarate/malate translocator from spinahc chloroplasts. J. Bacteriol. 180, 4160-4165.

Rauter, M., Prokoph, A., Kasprzak, J., Becker, K., Baronian, K., Bode, R., et al. (2015). Coexpression of Lactobacillus brevis ADH with GDH or G6PDH in 
Arxula adeninivorans for the synthesis of 1-(R)-phenylethanol. Appl. Microbiol. Biotechnol. 99, 4723-4733. doi: 10.1007/s00253-014-6297-z

Schwaneberg, U., Otey, C., Cirino, P. C., Farinas, E., and Arnold, F. H. (2001). Cost-efficient whole-cell assay for laboratory evolution of hydroxylases in Escherichia coli. J. Biomol. Screen. 6, 111-117. doi: 10.1177/1087057101006 00207

Spaans, S. K., Weusthuis, R. A., van der Oost, J., and Kengen, S. W. M. (2015), NADPH-generating systems in bacteria and archaea. Front. Microbiol. 6, 1-27. doi: 10.3389/fmicb.2015.00742

Straathof, A. J., Panke, S., and Schmid, A. (2002). The production of fine chemicals by biotransformations. Curr. Opin. Biotechnol. 13, 548-556. doi: $10.1016 /$ S0958-1669(02)00360-9

Studier, F. W. (2005). Protein production by auto-induction in high-density shaking cultures. Protein Expr. Purif. 41, 207-234. doi: 10.1016/j.pep.2005.01.016

Tufvesson, P., Lima-Ramos, J., Al Haque, N., Gernaey, K. V., and Woodley, J. M. (2013). Advances in the process development of biocatalytic processes. Org. Process Res. Dev. 17, 1233-1238. doi: 10.1021/op4001675

van der Donk, W. A., and Zhao, H. (2003). Recent developments in pyridine nucleotide regeneration. Curr. Opin. Biotechnol. 14, 421-426. doi: 10.1016/S0958-1669(03)00094-6

Vasquez, B., and Reeves, H. C. (1979). NADP-specific isocitrate dehydrogenase of Escherichia coli. Biochim. Biophys. Acta - Protein Struct. 578, 31-40. doi: 10.1016/0005-2795(79)90109-0

Wichmann, R., and Vasic-Racki, D. (2005). Cofactor regeneration at the lab scale. Adv. Biochem. Eng. Biotechnol. 92, 225-260. doi: 10.1007/b98911
Wu, H., Tian, C., Song, X., Liu, C., Yang, D., and Jiang, Z. (2013). Methods for the regeneration of nicotinamide coenzymes. Green Chem. 15:1773. doi: $10.1039 / \mathrm{c} 3 \mathrm{gc} 37129 \mathrm{~h}$

$\mathrm{Xu}, \quad$ F. (2005). Applications of oxidoreductases: recent progress. Ind. Biotechnol. 1, 38-50. doi: 10.1089/ind. 2005.1.38

Zhao, H. (2005). Effect of ions and other compatible solutes on enzyme activity, and its implication for biocatalysis using ionic liquids. J. Mol. Catal. B Enzym. 37, 16-25. doi: 10.1016/j.molcatb.2005. 08.007

Zheng, Y., Yin, H., Yu, D., Chen, X., and Tang, X. (2017). Recent advances in biotechnological applications of alcohol dehydrogenases. Appl. Microbiol. Biotechnol. 2017, 987-1001. doi: 10.1007/s00253-0168083-6

Conflict of Interest Statement: The authors declare that the research was conducted in the absence of any commercial or financial relationships that could be construed as a potential conflict of interest.

Copyright (๑) 2018 Oeggl, Neumann, Gätgens, Romano, Noack and Rother. This is an open-access article distributed under the terms of the Creative Commons Attribution License (CC BY). The use, distribution or reproduction in other forums is permitted, provided the original author(s) and the copyright owner(s) are credited and that the original publication in this journal is cited, in accordance with accepted academic practice. No use, distribution or reproduction is permitted which does not comply with these terms. 